WellBeing International

WBI Studies Repository

1998

\title{
Attitudes and Dispositional Optimism of Animal Rights Demonstrators
}

\author{
Shelley L. Galvin \\ Western Carolina University \\ Harold A. Herzog \\ Western Carolina University
}

Follow this and additional works at: https://www.wellbeingintlstudiesrepository.org/acwp_awap

Part of the Animal Studies Commons, Civic and Community Engagement Commons, and the Politics and Social Change Commons

\section{Recommended Citation}

Galvin, S. L., \& Herzog, H. A. (1998). Attitudes and dispositional optimism of animal rights demonstrators. Society \& Animals, 6(1), 1-11.

This material is brought to you for free and open access by WellBeing International. It has been accepted for inclusion by an authorized administrator of the WBI Studies Repository. For more information, please contact wbisr-info@wellbeingintl.org.

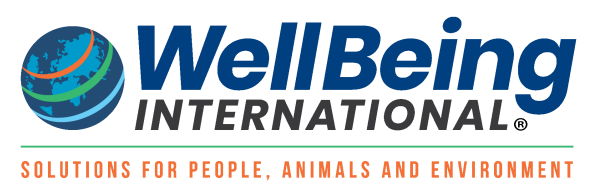




\title{
Attitudes and Dispositional Optimism of Animal Rights Demonstrators
}

\author{
Shelley L. Galvin \\ MARS HILL COLLEGE \\ Harold A. Herzog, Jr. \\ WESTERN CAROLINA UNIVERSITY
}

\begin{abstract}
Mail-in surveys were distributed to animal activists attending the 1996 March for the Animals. Age and gender demographic characteristics of the 209 activists who participated in the study were similar to those of the 1990 March for the Animals demonstrators. Most goals of the animal rights movement were judged to be moderately to critically important, although beliefs about their chances of being realized varied considerably. Movement tactics judged to be least effective included the liberation of laboratory animals and the harassment of researchers. Education was seen as being a particularly important instrument of future social change. Demonstrators' scores on the Life Orientation Test - a measure of dispositional optimism - were significantly greater than scores of comparison groups of college students and of patients awaiting coronary bypass surgery. There was a significant positive relationship between levels of optimism and activists' perceptions of the achievement of movement objectives.
\end{abstract}

Over the past 20 years, the animal rights movement has become an established part of American sociopolitical culture. Efforts by animal activists have resulted in substantial changes in attitudes toward other species and in the enactment of legislation pertaining to their treatment. The number of Americans identifying themselves with the movement increased dramatically throughout the 1980's $s$ as did the financial status of both moderate and more radical animal protection organizations (Guillermo, 1993; Jasper \& Nelkin, 1992).

One of the more notable events in the history of the contemporary animal rights movement was the 1990 March for the Animals in Washington, D.C. Attracting approximately 25,000 demonstrators, it was the first major show of strength of the animal rights movement in the United States. It also provided social scientists with an opportunity to study the psychology and sociology of animal activism. Plous (1991) and Jamison and Lunch (1992) used on-the-spot interviews to examine aspects of the demographics and attitudes of the demonstrators. We used mail-back surveys of individuals attending the march to examine the personal moral philosophies of animal activists and found that the demonstrators were more "absolutist" in moral orientation (more idealistic and less relativistic) than a comparison group of college students (Galvin \& Herzog, 1992).

Six years after this event, the National Alliance for Animals organized World Animal Awareness Week, which culminated in the 1996 March for the Animals. The second march, held on June 23, 1996, was 
intended as a follow up of the 1990 demonstration and was intended as a show of movement unity and strength. The 1996 march attracted only about 3,000 demonstrators (Lipton, 1996), considerably less than the earlier event. It is unclear whether the reduced participation was an indicator of decreased public interest in animal welfare issues (Herzog, 1996; Rowan \& Shapiro, 1996).

We used the 1996 march as a second opportunity to survey animal activists. We were particularly interested in the following aspects of the demographics and the attitudes of demonstrators:

a. changes in the gender and age composition of animal activists since the 1990 march;

b. the perceived importance of specific goals of the animal protection movement;

c. activists' assessments of the likelihood that the goals would be achieved within 15 years;

d. perceptions of the past and future effectiveness of various movement tactics;

e. the relationship between dispositional optimism and perceptions of the future success of the animal protection movement.

Methods

The methods used in this study paralleled those used in our investigation of demonstrators at the 1990 march. On the morning of June 23, 1996, as people gathered on the Ellipse in Washington, D.C., we approached 750 participants on an ad hoc basis, explained to them our interest in their opinions, and asked them to fill I out a survey and return it by mail via a pre-addressed, postage-paid envelope that we supplied.

Materials

The survey contained four sections.

1. Demographics. Participants were asked to indicate their sex, age, whether or not they considered themselves to be an animal activist, and the length of their involvement in the movement.

2. Movement objectives. The demonstrators were asked to evaluate the importance of nine movement objectives on a five-point scale ranging from "not at all important" to "critically important." The goals included the cessation of the use of animals for biomedical research, consumer product testing, meat, dissection, leather, sport hunting, zoos and circuses, and companion animals. The participants were also asked to estimate the likelihood that the goal would be reached within the next 15 years. On this scale, a 0 meant that they believed that there was no chance that the objective would be achieved, whereas 100 percent indicated that they were certain that the goal would be realized.

3. Effectiveness of movement tactics. The respondents were asked to evaluate the importance of eight strategies employed by animal protectionists. These included lobbying legislative bodies, boycotting companies involved in animal testing, attending marches and demonstrations, liberating laboratory animals, harassing animal researchers, taking legal actions on behalf of animals, conducting educational efforts directed at elementary and secondary students, and modeling cruelty- free lifestyles. Participants rated both the past and future importance of each tactic on a five-point Likert scale from "none" to "critical." Space was also provided for activists to indicate strategies of importance not listed on the questionnaire.

4. Dispositional optimism. Part three consisted of the Life Orientation Test, a scale developed by Scheier and Carver (1985) to assess optimism as a psychological trait. Dispositional optimism has been found to be related to variables such as the ability to cope with psychological and physical stress (Aspinwal \& Taylor, 1992; Scheier, Carver, \& Bridges, 1994; Scheier, Weintraub, \& Carver, 1986). We used the revised version (LOT-R) (Scheier, Carver, \& Bridges, 1994), which 
consists of 10 statements, four of which are dummy items. Of the six used to assess optimism, three were reverse worded. Sample items included "In uncertain times, I usually expect the best," "If something can go wrong for me, it will," and "I'm always optimistic about my future." Scores on the scale can range from 0 to 24 . The authors of the revised version reported a Cronbach's alpha of.78 with test-retest reliabilities ranging from .56 to .79 over time periods ranging from 4 to 28 months.

We hypothesized that animal activists would have high LOT-R scores com- pared to non-activists. For our comparison groups, we used unpublished data provided by Scheier and Bridges from college students (n $=1505)$ and patients awaiting coronary surgery $(n=284)$. We also anticipated that among activists there would be a positive correlation between individual differences in LOT-R scores and differences in judgements about the chances of the movement objectives being realized.

Attitudes toward animal use. The activists were asked about their beliefs about nine statements generally related to the treatment of animals. (This data was obtained as part of a separate study and will not be described here.)

Results

\section{Age and Gender}

Two hundred thirty-one participants returned questionnaires, a response rate of $33 \%$ (as compared to a $26 \%$ return rate for our 1990 study). Surveys were returned from 34 states. Thirty-nine percent of the respondents were from New York, Virginia, Maryland, and New Jersey. Three percent of the respondents were from outside of United States. Twenty-two of the respondents indicated that they did not consider themselves to be animal activists (we omitted these from the data analysis, leaving 209 in the final data set).

Of the activists who returned the survey, 153 were women and 55 were men (one did not indicate gender). Thus, $74 \%$ of the sample of demonstrators were women, a proportion very similar to the $77 \%$ that we obtained in our 1990 study.

The participants ranged in age from 13 to 70 years old, with a median age of 34 which, again, was similar to activists attending the 1990 march (median age $=32$ ). The median length of time the respondents were involved in the movement was 6 years (range $=1$ to 40 ). This length of involvement is twice as long as reported by the respondents of our 1990 study in which the median was three years (Herzog, 1995).

\section{Animal Rights Movement Goals}

The participants' mean ratings of the relative importance of each of the nine goals and the likelihood of their being achieved within the next 15 years are shown, in Table 1, in order of perceived importance. Eight of the nine objectives were judged to be moderately or critically important. The exception was the elimination of companion animals; only $13 \%$ of the activists felt that this was an important objective for the animal rights movement.

While there was little variation in the perceived importance of the goals, there were considerable differences in judgements of the likelihood that they would be achieved. Only three of the most important goals were judged to have better than a $50 \%$ chance of being accomplished (an end to consumer product testing on animals, trapping wild animals for their fur, and the use of animals for dissection in educational settings). Stopping the use of animals in biomedical research was judged to have only a $41 \%$ chance of 
being attained. Putting an end to the consumption of animal flesh, by far the largest category of animal use in American culture, was judged to have a particularly low chance of being achieved (21\%).

Table 1. Mean ratings of importance and likelihood of achieving of movement goals.

\begin{tabular}{|lcccc|}
\hline & \multicolumn{2}{c}{ Importance rating } & \multicolumn{2}{c|}{$\begin{array}{c}\text { Likelihood of } \\
\text { achievement }\end{array}$} \\
Goal & M & SD & M & SD \\
\hline Consumer product testing & 4.98 & 0.15 & $79.3 \%$ & $23.25 \%$ \\
Animal trapping for fur & 4.92 & 0.25 & $68.2 \%$ & $29.1 \%$ \\
Dissections in public schools & 4.88 & 0.43 & $73.0 \%$ & $26.2 \%$ \\
Biomedical research & 4.87 & 0.35 & $41.3 \%$ & $35.6 \%$ \\
Sport hunting & 4.64 & 0.41 & $39.8 \%$ & $31.8 \%$ \\
Meat consumption & 4.67 & 0.67 & $20.9 \%$ & $26.5 \%$ \\
Animals in zoos and circuses & 4.64 & 0.64 & $39.4 \%$ & $30.2 \%$ \\
Use of leather products & 4.56 & 0.72 & $26.5 \%$ & $27.3 \%$ \\
Companion animals & 1.95 & 1.22 & $4.8 \%$ & $16.5 \%$ \\
\hline
\end{tabular}

\section{Tactics of the Animal Rights Movement}

The mean ratings of the effectiveness of movement tactics are shown in Table 2. Repeated measures MANOVA indicated a significant difference $[F(7,1400)=53.52, p<.001]$ among the ratings of the past effectiveness of the eight strategies. Tukey post-hoc analysis for repeated measures indicated that company boycotts were perceived as the most effective strategy, except setting personal examples. Next were (of more or less equal importance) educating students in schools, lobbying for protective legislation, taking legal actions on behalf of animals, and participating in marches or demonstrations; these tactics, however, were judged significantly less effective than conducting company boycotts. Liberating animals from laboratories was seen as less effective than any other strategies, except for harassing animal researchers, which was ranked the least effective of all.

Table 2. Perceived effectiveness of movement strategies

\begin{tabular}{|lcccccc|}
\hline & \multicolumn{2}{c}{ Future } & \multicolumn{2}{c}{ Past effectiveness } & Future & Past \\
effectiveness & M & SD & M & SD & & rank \\
\hline Edrategy & 4.85 & 0.43 & 4.16 & 1.14 & 1 & 6 \\
Company boycotts & 4.79 & 0.54 & 4.50 & 0.83 & 2 & 1 \\
Legal action for animals & 4.76 & 0.51 & 4.24 & 1.01 & 3 & 4 \\
Lobbying for protective laws & 4.68 & 0.71 & 4.20 & 1.03 & 4 & 5 \\
Setting personal examples & 4.69 & 0.67 & 4.35 & 1.03 & 5 & 2 \\
Marches and demonstrations & 4.36 & 0.85 & 4.25 & 0.94 & 6 & 3 \\
Liberating lab animals & 4.11 & 1.18 & 3.99 & 1.67 & 7 & 7 \\
Harassment of animal & 3.18 & 1.45 & 3.06 & 1.33 & 8 & 8 \\
researchers & & & & & & \\
\hline
\end{tabular}

The ratings of the future effectiveness of these strategies also differed significantly $[F(7,1400)=63.78$, $p<.001]$. Tukey post-hoc analysis indicated that activists rated education in the elementary and 
secondary schools, company boycotts, taking legal actions on behalf of animals, lobbying for protective laws, and setting personal examples as equally effective to each other in future goal attainment. These tactics were judged to be the most significant of the strategies. Marches and demonstrations were projected to be significantly more effective than liberating lab animals and harassment of animal researchers. Liberating lab animals was thought to be significantly more effective than harassment of animal researchers. Harassment was rated as being the least effective future tactic.

There were significant differences between perceptions of the past and future effectiveness of some of the strategies. This shift was most pronounced in the case of education in elementary and secondary schools, which was judged to be the sixth most effective strategy in the past but which jumped to first place for the projected future effectiveness. Setting personal examples and participating in marches or demonstrations, rated second and third most effective in the past, dropped to fifth and sixth places, respectively, for projected future importance. The most controversial tactics, liberating lab animals and harassment of animal researchers, were ranked last in both past and future effectiveness.

Sixty-four activists described other tactics that they perceived to be effective in furthering the cause of animals. The majority of these responses focused on education of the general public and members of the medical, scientific, and legal communities. Specific strategies included presenting more media coverage of animal issues, writing letters to editors, sponsoring paid advertisements, distributing leaflets, conducting grassroots door-to-door campaigns, participating in "word of mouth" activities, and producing and distributing videotapes documenting atrocities and/or acceptable alternatives.

Some respondents advocated an increase in direct action and/or civil disobedience. These included "forceful, nonviolent confrontations," adopting "an extremely attractive and effective ... peaceful, nonthreatening spiritual approach," and "developing a strong, positive language and a loving, tolerant manner." Several respondents commented on the futility of violence and "extremism [that] turn off people whom the movement needs." One felt that there was a critical need to "create a positive image of the movement - no harm to anyone." A small number of respondents advocated more violent actions such as "monkey wrenching," "economic sabotage," "spray painting and ransacking expensive fur coat stores." and "targeting strategic high-profile situations." However, none of the respondents advocated physically harming their opponents.

Several respondents called for the movement to join forces with other groups with compatible aims such as the Nature Conservancy and the Sierra Club. One suggested mainstreaming the movement and/or the movement's publications "to appeal to ... Middle America's heart and good sense." Others suggested seeking the support of the religious community. Several respondents indicated a need for "more solidarity" and "stopping the arguing among the sub-groups within the movement."

\section{Optimism and Animal Activism}

The LOT-R scores ranged from 6 to 24 with a mean score of 16.26 (SD = 3.59). We compared these scores with LOT-R scores obtained recently by Bridges and Scheier (personal communication, 1997) on a sample of 1,505 college students $(M=14.21, S D=4.66)$ and a sample of 284 patients awaiting coronary bypass surgery $(M=15.35, S D=3.91)$. The animal activists were significantly more optimistic than either of these groups (students: $Z=7.36, p<.001$; patients: $Z=2.66, p<.01$ ). We hypothesized that activists with high LOT-R scores would also be more optimistic in their estimates of the likelihood that the movements' goals would be achieved. An overall likelihood score was calculated for each respondent by averaging the ratings of confidence in the achievement of each of the nine goals. Overall likelihood scores ranged from $3 \%$ to $99 \%$ with a mean score of $48 \%(S D=20.8)$. A modest, but significant, positive 
relationship was found between optimism scores and overall likelihood of success scores (Pearson $r=$ $.23, p<.01)$

Discussion

Our demographic data suggest that the animal rights movement has not been successful in broadening the gender distribution of its base over the six years intervening between the two Marches for the Animals. Animal rights groups continue to draw their support predominantly from women, and there is no evidence that men are currently attracted to the cause of animals in proportion to their numbers in the population.

We did find, however, that the median age of the respondents was slightly greater in the 1996 March and that the participants claimed to have been involved in the movement for about twice as long as those attending the 1990 event. This finding suggests that the movement may be not attracting new recruits in sufficient numbers to maintain the growth witnessed in the 1980's. The fact that the 1996 March drew markedly fewer participants than expected by the organizers supports this notion. Alternatively, this finding may reflect a more mature movement, one that has been around for six more years.

In general, the respondents indicated they believed that almost all of the goals of the movement were very important with the exception of the elimination of companion animals. Some goals were seen as being realistically within reach, whereas others were not. The goals that were seen as most likely to be achieved (the areas of product testing on animals, trapping animals for fur, and the use of animals in school dissections) are areas in which there has been visible social change over the past 20 years. On the other hand, the goals seen as least likely to be achieved involved areas in which the vast majority of animals are used by humans - food and clothing. Thus the activists' views of the likelihood that goals would be achieved reflected a realistic assessment of movement successes and of barriers to future success.

All of the strategies used by animal activists were perceived as being at least somewhat effective. Strategies that were perceived as having been most effective were boycotts of companies involved in animal testing, setting personal examples, and marches and demonstrations. The most disruptive tactics (harassment of researchers and the liberation of laboratory animals) were perceived as having been the least effective. Educating elementary and secondary school students to the importance of ethical issues showed the greatest shift between past and future importance.

\section{Optimism and Animal Activism}

Why are some people and not others attracted to social movements? We suggest that a disposition toward an optimistic worldview, coupled an idealistic moral absolutism, is an important component in the psychology of social activism. Scheier et al. ( 1994) argue that efforts to overcome adverse situations depend upon positive perceptions that the goals will be successfully attained. This expectancy value model is directly related to the dynamics of social activism; people should be attracted to and remain involved in movements as long as they believe there is a reasonable possibility that a given movement's goals will be achieved.

Our findings provide some support for this view. We found that animal rights demonstrators had higher levels of optimism than college students or coronary bypass patients. We also found that there was a tendency for more optimistic activists to have a more favorable belief in the attainment of movement goals in the future. 
This data, however, needs to be viewed with caution in that there are several possible sources of bias. First, more optimistic activists may have been more likely to attend the March or to mail back the survey than those with a more pessimistic outlook. Indeed, we would expect this to be the case. To date, studies of animal activists have focused on those who join organizations, subscribe to animal rights magazines, and attend meetings and demonstrations (Galvin \& Herzog, 1992: Jamison \& Lunch, 1992; Jasper \& Nelkin, 1992; Jasper \& Poulsen, 1995; Paul, 1995; Plous, 199 1; Richards \& Krannich, 1991 ). Nothing is known of the psychology of individuals who are sympathetic to the aims of, and identify with, the animal rights movement but who remain "on the sidelines." We would predict that these individuals would have lower LOT-R scores than those who act on their beliefs. In the future, the study of social movement bystanders may prove a fertile area of research for social scientists interested in why individuals become social activists.

A second concern is the assumption that optimism is a disposition - that it has the characteristics of a psychological trait. It is certainly possible that LOT-R scores could also be influenced by situational factors. Indeed, some activists may have had depressed LOT scores because of the unexpectedly low turnout at the 1996 March. On the other hand, some activists may have had elevated scores because of enthusiasm engendered by the event. While it is important to acknowledge these potential sources of bias, we feel that the relationship between optimism and activism is a fruitful avenue for further research.

\section{References}

Aspinwal, L. G. \& Taylor, S. E. (1992). Modeling cognitive-adaptation: A longitudinal investigation of the impact of individual differences and coping on college adjustment and performance. Journal of Personality and Social Psychology, 63, 989-1003.

Galvin, S. \& Herzog, H. A., Jr. (1992). Ethical ideology, animal activism and attitudes toward the treatment of animals. Ethics \& Behavior, 2, 141-149.

Guillermo, K. S. (1993). Monkey business. Washington: National Press Books.

Herzog, H. A., Jr. (1995). The psychology of animal rights activism. In A. M. Goldherg \& L. F. M. van Zutphen (Eds.), Proceedings of the World Congress on Alternatives and Animal Use in the Life Sciences: Education, Research, Testing (pp. 663-668). New York: Mary Ann Liebert Publishers.

Jamison, W. \& Lunch, W. (1992). The rights of animals, science policy and political activism. Science Technology and Human Values, 17, 438-458.

Jasper, J. M. \& Nelkin, D. (1992). The animal rights crusade: The growth of a moral protest. New York: The Free Press.

Jasper, J. M. \& Poulsen, J. D. (1995). Recruiting strangers and friends: Moral shocks and social networks in animal rights and anti-nuclear protests. Social Problems, 42. 493- 512.

Lipton, E. (1996, June 24). Adamant about animal rights. The Washington Post, B3.

Paul, E. (1995). Us and them: Scientists' and animal rights campaigners' views of the animal experimentation debate. Society and Animals, 3, 1-21.

Plous, S. (1991). An attitude survey of animal rights activists. Psychological Science. 2, 194-196. 
Richards, R. T. \& Krannich, R. S. (1991). The ideology of the animal rights movement and activists' attitudes toward wildlife. Transactions of the 56th North American Wildlife and Natural Resources Conference.

Rowan, A. \& Shapiro, K. J. (1996). Animal rights: A bitten apple. American Psychologist. 51, 1183-1184.

Scheier, M. F. \& Carver, C. S. (1985). Optimism, coping, and health: Assessment and implications of generalized outcome expectancies. Health Psychology, 4(3), 219-247.

Scheier, M. F., Carver, C. S., \& Bridges, M. W. (1994). Distinguishing optimism from neutoticism: A reevaluation of the Life Orientation Test. Journal of Personality and Social Psychology, 67(6), 1063-1078.

Scheier, M. F., Weintraub, J. K., \& Carver, C. S. (1986). Coping with stress: Divergent strategies of optimists and pessimists. Journal of Personality and Social Psychology. 51(6), 1257-1264. 